\title{
ACAECERES EN LA VIDA DE JUCE GOTINA, SASTRE JUDÍO DE LA VILLA DE ÉPILA (SIGLO XV)
}

ENCARNACIÓN MARÍN PADILLA CSIC. Madrid

En todas las comunidades, sea cual sea su credo religioso, la relación y convivencia entre los miembros que la forman no han estado exentas de disputas, peleas, rencores, envidias, chismes, murmuraciones, calumnias, etc. Clara muestra de las difíciles relaciones humanas, y concretamente en el siglo $\mathrm{XV}$, son los muchos instrumentos públicos notariales de los Archivos de Protocolos que a ellas aluden y cuya solución quedaba en manos de árbitros o amigables componedores, propuestos por las partes en litigio, o ante la corte de las personas que ostentaban la jurisdicción del lugar, en primera instancia.

La comunidad judía de Épila, villa aragonesa de la que fueron señores los Ximénez de Urrea, no iba a verse libre de estos casos. Entre las personas conflictivas que durante el siglo $\mathrm{XV}$ vivieron en ella, se encontraba el sastre Juce Gotina. De algunos aspectos de su vida me ocuparé en estas páginas '.

Una rama de la familia judía Gotina aparece residiendo en Épila desde la segunda década del siglo XV, cuando adquirió uno de ellos, el zapatero Jaco, una "casa o tanyeria».

La residencia de Jaco Gotina en Épila pudo estar motivada por los intereses económicos que su padre, el mercader zaragozano Nahamen Gotina, tenía en la villa. Además de su profesión de zapatero, Jaco se dedicó a hacer entregas en comandas a cristianos y, sobre todo, a moros de Épila y a los que residían en lugares

${ }^{1}$ Su base documental procede del Archivo de Protocolos Notariales de La Almunia de Doña Godina (L.A.APN.). Todas las personas nombradas residieron en Épila, villa donde ocurrieron los hechos narrados; si no fuera así, se hará constar. 
cercanos; pero estos préstamos nunca llegaron a ser de la importancia y cuantía de los que hizo su padre en dicha villa.

En 1430 Jaco Gotina era adelantado de la aljama, junto con Simuel Alcarahuey y Salamon Sumiel, y en los años siguientes, poseedor de varios inmuebles. En 1455 tenía un corral en el barrio de El Puniello, pero parece que su residencia la tuvo en el barrio de El Burgo, en unas casas que lindaban con las de rabí Abraham Albo y de su hijo Juce Albo. Sus otras casas de la Plaza, que lindaban con el hospital de los pobres cristianos y que le vendieron sus padres, Nahamen Gotina y Estruga Albala, en 1453 - junto con todos los bienes muebles e inmuebles que tuvieron en la villa, sus términos y los de Suñén, entre los que se encontraban tres camposno le ocasionaron pocas preocupaciones: un requerimiento ante el lugarteniente del justicia, por filtración de agua, y varios ante el propio justicia cuando se las vendió a Acach Sumiel, pues el escudero Gonzalvo de Arbués se creyó con derecho a comprarlas por haber pertenecido siempre a sus parientes cercanos, los Suñén... ${ }^{2}$.

Expuestos los antecedentes familiares, paso a hablar del sastre Juce Gotina, hijo de Jaco, nieto de Nahamen y de Estruga Albala y hermano de Abraham Gotina.

Juce Gotina vivió en el barrio de Las Eras, en unas casas que lindaban con las de dos cristianos y con carreras públicas por dos partes.

Aunque con menos frecuencia que su padre Jaco, Juce entregó en comandas, desde 1445 hasta 1460 y ante el notario Martín Marín, un total de ochenta cahíces veintitrés fanegas dos arrobas de trigo, siete cahíces una arroba de ordio, seis cahíces y medio de avena y cuatrocientos ochenta y tres sueldos a cristianos, y a los moros de Épila o residentes en lugares cercanos, como Lumpiaque, Mesones, Rueda, Salillas y Suñén. Estas comandas obligaron a Juce, a veces, a entregar a sus deudores grano para la siembra y a requerir al justicia para que ordenara emparar bienes de los mismos, cuando no le pagaban.

Juce debió de ser algo impetuoso y de carácter difícil, a lo que

${ }^{2}$ El matrimonio Nahamen Gotina-Estruga Albala las había comprado a Martín de Suñén. Dada la limitación de páginas de este homenaje y porque de todo lo que aquí expongo doy más extensas noticias en mi trabajo, La villa aragonesa de Épila en el siglo XV: sus judios (en prensa), prescindiré de las notas que no son base fundamental de éste. 
pudo contribuir, o tal vez fue la causa, el comportamiento de su mujer, posiblemente Mira de Çuri. En 1445 el matrimonio se vio envuelto en un litigio basado en el posible adulterio de ella, según comentaba Ester, hija de Ezdra Gaddax y mujer del jubonero Juce Albo, y en los hurtos que se atribuían a los dos.

El 8 de abril de dicho año, en las casas del adelantado Jossuas Gallur, ante el merino Miguel de Fuertes y en presencia del notario cristiano y los testigos, compareció Juce Gotina y les dijo:

"-Merino e adelantado, yo me represento a vosotros, asi como a judges que soys, diputados de la aljama"

por el señor don Lope Ximénez de Urrea, diciendo:

"-Ami, mi, mi, fuerça, fuerça, como yo tenga mi muller segunt mi voluntat e condicion buenha, honesta e de buenha fama, e ... Ezter ... aya clamado a mi muller puta, bagassa, que se hatava con Miguel de Soria ... e que aquel fillo que yo tengo en ella ys del, no mio et encara le aya dito que se torne al Almunya e quel aniello que Pedro ${ }^{3}$... que mi muller lo havia furtado. Et mas abant que los XX florines que se havian caydo a Mosse Afra, judio de Caragoça, aqui en Epila, que yo me los havia trobado e que aquellos me fazian sallir de dreyto; porque vos requiero con grant instancia e encara tornando a reduzirvos a memoria a mi voz de apellido diziendo: Ami, mi, mi, que la dita Ezter sea de continent presa e que por su preso ella maniffieste legitimament mi muller no haver caydo en los ditos delittos por ella a nosotros increpada, que quiero que mi muller pase penitencia por el delitto por ella contra mi comesa, segunt fuero del Regno e hordinacion de ley de judios, e por stablecer si ella ni yo havemos preso los robos sobreditos, que padezcamos pena por aquella, e do no, que ella se pora ad aquella pena o penas que son atribuidas a personas que senblantes cosas opposan a nosotros o a senblantes otros a fazer; protestando contra vosotros de las penas que contra vosotros sobre aquesto porian seyer imposadas por la tarda e negligencia de vosotros".

A continuación, Juce requirió al notario para que levantara acta de su petición. Entonces el merino y el adelantado, sin admitir las

${ }^{3}$ Espacio en blanco. 
protestas hechas contra ellos, respondieron que si contra ambos se hacía el acta, que no la cerrase el notario sin que ellos contestaran ${ }^{4}$.

No consta cómo terminó la cuestión ni si fue real tal adulterio y los hurtos, pero el 7 de mayo el merino y el adelantado entregaron a Juce Gotina en "caplieuta", a Acach de Leredi y a Salamon Gotina, mayor, para que el domingo siguiente lo dejaran en la prisión del merino, bajo pena de diez florines ${ }^{5}$.

Si rabí Abraham Albo intervino en el caso y actuó según la "hordinacion de ley de judios", a la que Juce aludió, ésa pudo ser la causa de que éste y su madre insultaran al rabí con

"palavras fehas, injuriosas e encara en presencia de los adelantados e de aquestos otros judios buenos ... e de otra part dichas al aljama, a mayores, medianos e menores, palavras muy fehas, vituperiosas e ... desonor e sutzias".

Se comentaba, además, entre los judíos que se había escrito a don Francisco Muñoz, procurador general del señor don Lope Ximénez de Urrea, refiriéndole justamente lo contrario y que el procurador, a su vez, envió una carta al merino para que averiguara lo ocurrido.

El sábado 31 de diciembre de 1446, en casa del merino Miguel de Fuertes, en presencia de los adelantados Salamon Sumiel y Sento Eli, de "honradas personas de judios» y ante el notario cristiano y los testigos, compareció rabí Abraham Albo y, después de referirse al caso, dijo:

"-Honorable merino, yo comparesco ante vos, asi como judio asignado al aljama e singlares de aquella ... constituydo por ... don Francisco ... porque en aquesta part el, asi como a judge, senyor e representante de la persona de mi senyor, ys forçado meter scarmiento en persona o personas que de tales cosas se anpran a dezir ni a fazer e que, como informacion de su animo e quel millor pueda judgar, si quiere terminar el negocio sobredito, que vos en su absencia querades tomar sumaria informacion de todo aqueste negocio ... e aquel vos lo querades abisar por vuestras letras de toda la verdad".

4 L.A.APN., Martín Marín, 1445, fols. 28v-29: testigo con el barbero Nicolás Buey, Acach Azan.

s Dicho notario y año, fol. 36: testigo con Lope de Pitiellas, Sento Alffrangil. 
A continuación, rabí Abraham pidió al merino que interrogara a los judíos presentes para

"contribuyr con mi e con todos los otros singlares ... e conozer ... la calidat e condicion, asi de mi como de todos los otros ... e vos querran notifficar ... si por mi son stadas dichas ni comesas dezir por ningun tiempo a ningunos de la aljama ni a singlares de aquella, palavras inrazonables e ultramesura, por las quales a ningunos pueda seyer opposadas en vituperio ni en desonor que vosotros los grandes dezir».

Entonces los adelantados respondieron, en «nombre e voz" de la aljama, que

"ni encara quanto a ellos podia seyer a memoria el dito rabi haver dito, comeso ni pronunciado palavras ningunas tales, por las quales el aljama sobredita ni ningun singlar de aquella sende deviese sentir. Et que quanto tocava por ellos ni tocar pudia, en nombre e boz de la dita aljama e por descargo dellos e de aquellos e aquellas, nuncha havian scripto ni enbiado a dezir con ninguno por palavra, palavras ningunas de ninguna clamor al sobredito procurador e que si ninguno las havia dito aquellas de continent devengavan, como dizieron devengavan ellos ni ninguno dellos haverlas ditas, hantes havian por mal que entre el dito rabi ni otro singlar de la dita aljama hovies debat ni question ninguna e que si aquella de present sigue hera por servicio de Dios ... antes nos podemos lohar e nos lohamos del sobredito rabi ... que quanto en el ys, a procurado e procura de todos dias en la utilidat e proveyto de la aljama e de los singlares de aquella e que do el deve seyer reverenciado e honrado por todos nosotros, nosotros ne haviesemos a dezir el contrario, fariamos mal e a toda sinrazon".

Cuando terminó la aclaración de los adelantados, rabí Abraham dijo al merino:

"-Creho bien el animo vuestro sia algun tanto bien informado de la relacion ante vos fecha por los sobreditos adelantados e aquestos honbres buenos de judios e havedes bien visto aquestas cosas opposadas contra mi devant del honorable procurador seyer no justas e inrazonablement opposadas. Et por tal que de todo lo sobredito a mi me pueda serbir bien a memoria e si quiere al honorable procurador e a bos", 
requirió al notario para que levantase una o muchas actas

«en conservacion de mi dreyto ... en su tiempo e saçon aquellas yo pueda demostrar».

Terminó diciendo rabí Abraham que las palabras que Juce y su madre profirieron contra él, las oyó Jaco Gotina que estaba allí, sin contradecirlas,

"como retando aquellas en tanto como si el me las dizia";

y que con dignos testigos estaba dispuesto a demostrarlo ante el procurador o cualquier juez o jueces que sobre el caso él mandara ${ }^{6}$.

No fue éste el único problema que rabí Abraham Albo mantuvo con los miembros de su comunidad, pero de eso hablaré en otra ocasión. Por lo que se refiere a Juce Gotina, en febrero de 1450 él y su mujer estaban de nuevo envueltos en un pleito, junto con Juce el Lumbroso, por razón de unas casas que el matrimonio vendió a Mahoma de Cepta. La causa del pleito constaba extensamente en un escrito de rabí Abraham Albo, notario de la aljama, y los adelantados tenían la cantidad que se pagó por ellas. Pero la complicación del caso hizo que cuando éste se presentó al merino, el mismo se asesorara con "savios e honbres de sciencia" de Zaragoza. Su sentencia fue favorable a Mahoma.

Pasan los años y en 1459 vuelven a surgir murmuraciones contra Juce Gotina por un posible rapto en la persona de Jamila Albala, hija de Salamon Albala, de la villa de Tauste, parienta suya.

El martes 23 de enero de dicho año, dentro de una cambra de las casas de Juce Eli, hijo de Salamon Eli, se encontraban el merino Juan Sánchez de Sarriá, el adelantado Ezdra Gaddax, Salamon Sumiel, mayor, el «rapaz» Jossuas Gallur, otros judíos buenos de la aljama y Jamila Albala. Ante todos ellos, el notario cristiano y los testigos, compareció el zapatero Abraham Gotina, mayor, y dirigiéndose al merino, le dijo:

"-Merino senyor, segunt que a mi notiçia ys preveydo e dado a entender, hoc encara fama publica ys por toda la villa de Epila, que mi hermano Juce Gotina se ha traydo de la villa de Tahust contra

6 Dicho notario, 1447, fols. 2-3; no aparece el nombre de los testigos. 
toda su voluntat e por fuerça aqui a la villa de Epila a Jamila Albala ...; porque merino, por verifficar la cosa asi como las gentes lo oppossan o no, pues ella misma ys en presencia vuestra e de aquestos buenos e honrados judios, que vos mismo la interrogueys e aquella por su bondat vos quiera dir con toda verdat si la cosa ys asi como las gentes lo dizen o si ys por el contrario".

Oído el requerimiento, por

"descargo suyo e por dar conto e razon al cargo de su officio",

el merino delante de todos los honrados judíos que estaban allí presentes, del notario y de los testigos, dijo a la interesada:

"-Jamila, yo asi como merino e judge qui so por el senyor don Lope ..., senyor de aquesta villa e de la aljama de los judios ..., vos requiero que vos con toda verdat me querades informar de todo aqueste fecho como ys venido, si en aquesta manera certifficado vos e con toda verdat, que si verdat ys como dizen, Juce Gotina ... vos ha traydo a aquesta villa por fuerça e contra vuestra voluntat, vos do palavra asi como a merino e judge que so de los judios de aquesta villa por el sobredito don Lope ... que yo vos complire del de toda justicia e manera que sia castigo del e exenplo de todos aquellos que lo oyran, porque vos torno a requerir e a rogar que vos me digais toda la verdat e que lo maniffestado de vos por vuestra propia boca pueda yo aquello adverar devant del sobredito senyor o devant de todos, aqui me querades adverar, si quiere notifficar, aqueste fecho de cómo fue puyado».

Jamila contestó así:

"-Merino senyor mio, he por bien entendido todo aquello que vos me ys stado requerido e allegado, porque vos digo e advero con toda verdat devant vuestra presencia e de todos lo[s] que aqui son con vos pressentes, que el dito Juce Gotina el qual dizen me ha traydo por fuerça ... de casa del sobredito don Salamon Albala, padre mio, e contra toda mi voluntat, que salva la honor e reverencia de todos aquellos que aquexo dizen ni diran, que dizen lo que les plaze e que no ys asi como ellos lo dizen ni diran ni lo han puesto en fama, antes vos digo de present e dire todavia que yo so venida a aquesta villa por mi voluntat propia e no por falago ninguno del 
dito Juce Gotina ni de otro ninguno, antes agora pora adagora absuelvo al dito Juce Gotina ante vos de aquellos e aquellas que sobre aqueste caso les pora seyer opposado caso malo ninguno, diziendo que personas otras algunas ayan tirado modo e manera como yo me sia venida a aquesta villa con el dito Juce Gotina, como yo no me clamo puton ni mas del dito Juce Gotina ni de otras personas ningunas, antes vos requiero que si sobre aqueste acto por vos dito merino ni por otro ninguno sea feyta carta publica ninguna, que en la fin de la carta publica vuestra o de aquellos todos a qui convendra seyer, sia inserta la present requesta mia».

Entonces el merino, "si quiere el sobredito Abraham Gotina", requirió al notario

«que por el descargo suyo les ne fizais la present carta publica»?

Al parecer y según las palabras de Jamila Albala, esta vez las murmuraciones contra Juce Gotina no fueron ciertas, aunque en 1476 Juce estaba casado con ella. El matrimonio vivía en el barrio de Las Herrerías y era dueño de un huerto en el término de «la penya el palacio»; a ellos me referiré en otra ocasión.

\section{RESUMEN}

Este estudio comenta algunos aspectos de la vida de Juce Gotina, sastre judío que residió en Épila, villa aragonesa del señorío de los Ximénez de Urrea, en el siglo XV. Juce fue hijo de Jaco Gotina y nieto del judío zaragozano Nahamen Gotina y de Estruga Albala.

\section{SUMMARY}

The present study analyzes some aspects of the life of Juce Gotina, a Jewish tailor who lived at Epila, an Aragonese village pertaining to the dominion of the Ximenez de Urrea family, in the 15th century. Juce was a son of Jaco Gotina and a grand-son of the Saragossan Jew Nahamen Gotina and of Estruga Albala.

${ }^{7}$ Dicho notario, 1459, fols. 10v-11v: testigo con el escudero f́nigo de Arbués, Salamon Levi. 